\title{
High School Dropout Intentions of Seventh Grade Pupils
}

Harry J. Parker

\section{TOD \\ LODAY, through all media, one hears and} reads of the necessity of students to complete at least the high-school diploma work. Industrial, business, and governmental agencies all stress the differential in salary potential for a high-school graduate and one without the basic background. Job application forms place additional emphasis upon a complete high-school background, the lack of which is generally the initial grounds for rejection. All of these aspects are realistic and reflect the compelling influences of education in a dynamic society.

Through all this discussion is the question of how substantial is the student's intention to terminate school before graduation. There seems to be no specific evidence in the literature that indicates if a dropout is a phenomenon conceived only at the high-school level, or if it possibly begins before high school. Generally, the highschool educator is confronted with such behavior, and frequently blamed for allowing it to arise, since the act of school termination is typically apparent at this level. Is this blame justified? One can ask if upper elementary-school students have fixed intentions about terminating high school before completion that would create reinforcement of this attitude in high school. The question which generates this article is the extent to which elementary students are expressing an intention to terminate education before high-school graduation.

The earlier an educator can perceive or obtain clues to the educational plans of students, the more effective guidance services and school personnel can be. Prevention is most frequently the desire of the educator, particularly where the behavior is detrimental to the individual.

As part of a voluntary, state-wide testing program in Oklahoma, sponsored by the Oklahoma State Department of Education, Frontiers of Science Foundation of Oklahoma, Inc., the Oklahoma Secondary-School Principals Association, and Science Research Asso-

Harry J. Parker is Associate Professor of Education, The University of Oklahoma, Norman, Oklahoma. 
ciates, a questionnaire, "Your Educational Plans," (YEP) ${ }^{1}$ was employed. Twenty-nine thousand seventh-grade students in 373 public schools, representing $66 \%$ of all enrolled seventh-grade students, were participants. Item six of the YEP represents the data which will provide the discussion for this article. The following table shows the response categories and the student reaction.

\section{SEVENTH-GRADE STUDENT INTENTION ABOUT COMPLETION OF HIGH SCHOOL}

Item 6: Some boys and girls hope to end their schooling as soon as possible and to begin earning money or managing a home. Some of them do not expect to finish high school. Do you think you will quit high school before you graduate? (Mark one answer only)

\begin{tabular}{|c|c|c|}
\hline & Boys* & Girls* \\
\hline & $N=14666$ & $N=14028$ \\
\hline A. Definitely will leave................ & $2.0 \%$ & $.7 \%$ \\
\hline 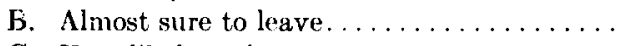 & $2.0 \%$ & $1.0 \%$ \\
\hline C. Very likely to leave................ & $3.0 \%$ & $1.3 \%$ \\
\hline D. Rather likely to leave...... & $2.4 \%$ & $1.0 \%$ \\
\hline E. Unlikely to leave......... & $17.0 \%$ & $11.1 \%$ \\
\hline 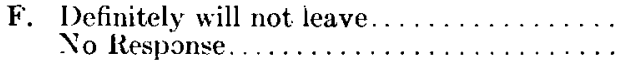 & $\begin{array}{r}73.0 \% \\
.6 \%\end{array}$ & $\begin{array}{r}81.2 \% \\
.7 \%\end{array}$ \\
\hline
\end{tabular}

* Differences between boys and girls in all categories were significant at the one per cent evel of confidence.

Responses $\mathrm{A}$ through $\mathrm{D}$ are viewed as degrees of disposition toward dropouts and show boys have significantly greater $(9.4 \%)$ inclination to drop out than do girls $(4.0 \%)$. Differences between boys and girls were statistically significant at the one per cent level of confidence. Thus responses $\mathrm{E}$ and $\mathrm{F}$ show girls stating more of a concern for remaining in high school $(95.3 \%)$, while boys indicated $90 \%$ inclination for finishing high school. Here, too, the differences between boys and girls were statistically significant at the one per cent level of confidence.

These data at least show that, at the seventh-grade level, the intentions for completion of high school are, in the main, reasonably well pronounced. As to why the dropout figures are from $30 \%-40 \%$ nationally is, of course, a matter of further study. ${ }^{2}$ There 1960.

1 "Your Educational Plans." Chicago, Illinois: Science Research Associates.

"James P. Mitchell. Manpower Challenge of the 1960's. Washington, D.C.: United States Government Printing Office. 1960. 
is no indication here that seventh-grade students have acquired this ultimate attitude or behavior at this particular grade level. It may be inferred that reinforcement or stimulus for drop out is peculiar to the eighth-grade and the high-school environment. It seems rather certain that other complicating factors appear at the eighth-grade and high-school levels to add to an individual's inclination to drop out of high school.

These data do not explain why students drop out. They do, however, suggest that at the seventh-grade level students are reasonably, if not nearly, sure of completing high-school work. There seems to be no evidence from this question and responses to suggest that the elementary school environment specifically provides unusual stimulus for drop out, to be reinforced by high-school experiences.

These data do suggest that more emphasis upon boys, in terms of guidance services, would be in order in view of their more apparent predisposition or intention to leave school when compared with girls.

Once again, the matter of dropout is not easily answered. However, there appears, at least from the data presented, no reason to consider the elementary school, at least the seventh grade, as the precipitating environment. Seventh-grade students do not appear to offer any strong evidence of intention to drop out of school. Certainly studies at the eighth and ninth grades might show remarkable changes. This would provide researchers and educators with an opportunity to focus at grades eight and nine for a study of the dropout problem.

While no blame or criticism is intended toward the high-school educator, these data on seventh-grade students suggest no reason to consider this grade level as a setting or the beginning of the dropout phenomenon. 